\title{
OBJECTIVE ASSESSMENT OF LAND USE IN HYDROGRAPHICAL STUDIES
}

\author{
ALFREDO RAMÓN MORTE, JOSÉ TOMÁS NAVARRO CARRIÓN \& ESTELA GARCÍA BOTELLA \\ University of Alicante, Spain
}

\begin{abstract}
The behaviour of floods depends on two main factors: Manning's roughness coefficient and the threshold runoff, $P_{0}$. In both parameters, land cover plays a vital role in the characterisation of small streams, which traditionally are altered in the Mediterranean basin. However, in the absence of an assessment protocol that optimises the geographical information stored in the official repositories, studies in these areas tend to be subjective, depending on the personal criteria of the technicians in charge of the study. In this paper a new method is proposed for the determination of these parameters, based on the integration of the Spanish national system for the mapping of flood-prone areas (SNCZI), which was designed by the Spanish Geological and Mining Institute (IGME), and the spatial data of the Spanish land cover and use information system (SIOSE database), designed by the Spanish National Geographic Institute (IGN). The methodology generates roughness data based on objective criteria and on a threshold runoff map, which can be reviewed by the technician in charge of the study, but which is based on updated, regulated and open official data. The result is a thorough hydrological and hydraulic characterisation, which has been tested in a western Mediterranean area characterised by the complexity of land use: the foothills between Sierra Helada and Sierra de la Cortina in the Municipality of Benidorm, located in the province of Alicante, Spain.

Keywords: flood risk, SIOSE, hazard, runoff, $P_{0}$.
\end{abstract}

\section{INTRODUCTION}

In the study of flood-prone areas, the behaviour of water is related, among other, to two main factors: the roughness coefficient defined by Manning's $n$ value, which demonstrates how the water will flow (hydraulic analysis), and threshold runoff, which shows how much water will flow (hydrological analysis). Threshold runoff is certainly one of the most sensitive and determining parameters in the study of flood risk.

Flood risk is defined by the amount of precipitation arriving to the superficial streams of the basin. Since the start of rain until the start of water flow, the soil absorbs water up to a limit that is determined by the threshold runoff reflected in the $P_{0}$ value, expressed in $\mathrm{mm}$. Once this threshold has been reached, water infiltrates only partially, generating a surplus that will become runoff [1]. When that happens, the soil is no longer able to absorb more water and it begins to flow over the ground across poorly defined flow paths. This is a key determinant in the hydrogeomorphological analysis for calculating the rainfall accumulation needed to generate those overland flows [2], in other words, the surface runoffs.

The study of this interrelation between rainfall and the runoff generated is a common practice used for the analysis of the hazard in the Mediterranean basins [3]. The generation of surface runoff at the level of these small-sized basins clearly represents a key process in the study of flood risk [2].

Because the definition of this parameter alters significantly the flow data collected through hydrometeorological methods, it is vital that this data is accurate when assessing the surface runoff in these basins, and when calculating the flow rates that will condition their water dynamics [4]. The more realistic the definition of baseline information is, the easier it will be to achieve results in line with reality. For this reason, it is necessary to 
ensure that the definition of the spatial variables involved in collecting this information is as realistic as possible.

Since runoff is the cause of the most difficult problems in basin management, active action is required in this part of the water cycle in order to prevent land damage caused by water [2]. An accurate characterisation is therefore vital for a deep understanding of the water cycle and behaviour of runoff when characterising a basin.

Accordingly, it was decided to choose a small-sized basin, which represented the type of basin typically found and liable to be the object of a flood risk assessment by request. This basin is located in the foothills of Sierra Helada in the Municipality of Benidorm, a province of Alicante. This is the perfect example of the type of Mediterranean basins discussed, typically ungauged and small-sized, where real flow rate data are not available and where there are high occupation and alteration rates.

\section{JUSTIFICATION}

When calculating the threshold runoff, it is necessary to use three spatial variables, slope, soil type and land use. The latter is the object of this detailed study. This parameter is usually calculated through the curve number method developed by SCS US Soil Conservation Service (SCS) in 1972 and adapted by Témez [5] for its use in Spain, and it was included in the reference document for its calculation in our country, "Instrucción de Carreteras 5.2" 1989 (Highway Instruction 5.2) (amended in 1990, 1998 and 2016) [2].

This document contains a table where threshold runoff was determined as a result of the combination of the three variables, and land use was the most dynamic one, which made it necessary to update information on a regular basis. From the beginning, the characterisation of land use based on this table had no choice but to resort to photo-interpretation techniques carried out by the technician in charge. For that reason, the allocation of land use was somewhat subjective, because it depended on the technician's personal criteria. The same area studied under different criteria may deliver fairly differentiated results.

This subjectivity causes questionable analysis. A method to avoid this uncertainty would be to employ official spatial data sources in the allocation of land use, such as CORINE Land Cover (CLC) and the Information System on Soil Occupation of Spain (SIOSE), which belongs to the Spanish National Plan for Land Observation (PNOT), scale $1: 50.000[6]$.

\section{METHODOLOGY}

In Spain, the background documents used in the calculation of both parameters are the Spanish National System for the Mapping of Flood-Prone Areas (SNCZI) [7] and the Highway Instruction 5.2 [8]. Thanks to their update in 2016, they have taken a big step towards the avoidance of the much feared subjectivity and towards a decrease in uncertainty in the allocation of land use, and they already include tables from the CLC for the definition of Manning's roughness coefficient and for the initial threshold runoff $\left(P_{0}\right)$ in $\mathrm{mm}$. Although this cartographic source is the one used and recommended by competent bodies in the field, its scale of work is clearly insufficient for the basins under study. This would require more specific and detailed flood risk assessment studies, since those basins hardly ever exceed $2 \mathrm{~km}^{2}$. For this reason, it is important to find a cartographic source to better represent this variable on a more appropriate scale.

The methodology proposed in this paper intends to go one step further and use the SIOSE database for the definition of both parameters on a suitable scale for these smallsized basins. This enables a meticulous analysis of the much sensitive parameters in flood 
risk assessment: threshold runoff and Manning's roughness coefficient, both which will be defined basing on updated, standardised and open official data.

In order to verify the possible variables in the result and to carry out that objective assessment of land use in hydrological studies, we have chosen an area representing the typical basins in southeast Spain, in the foothills of Sierra Helada in Benidorm, in the gently sloping watershed area, between the ravine Barranco de Barceló in the south, and the stream Rambla de Soler in the north. It is a $1.32 \mathrm{~km}^{2}$ basin in a highly disturbed area with a high degree of anthropic occupation and which has suffered significant changes in its land use (Fig. 1).

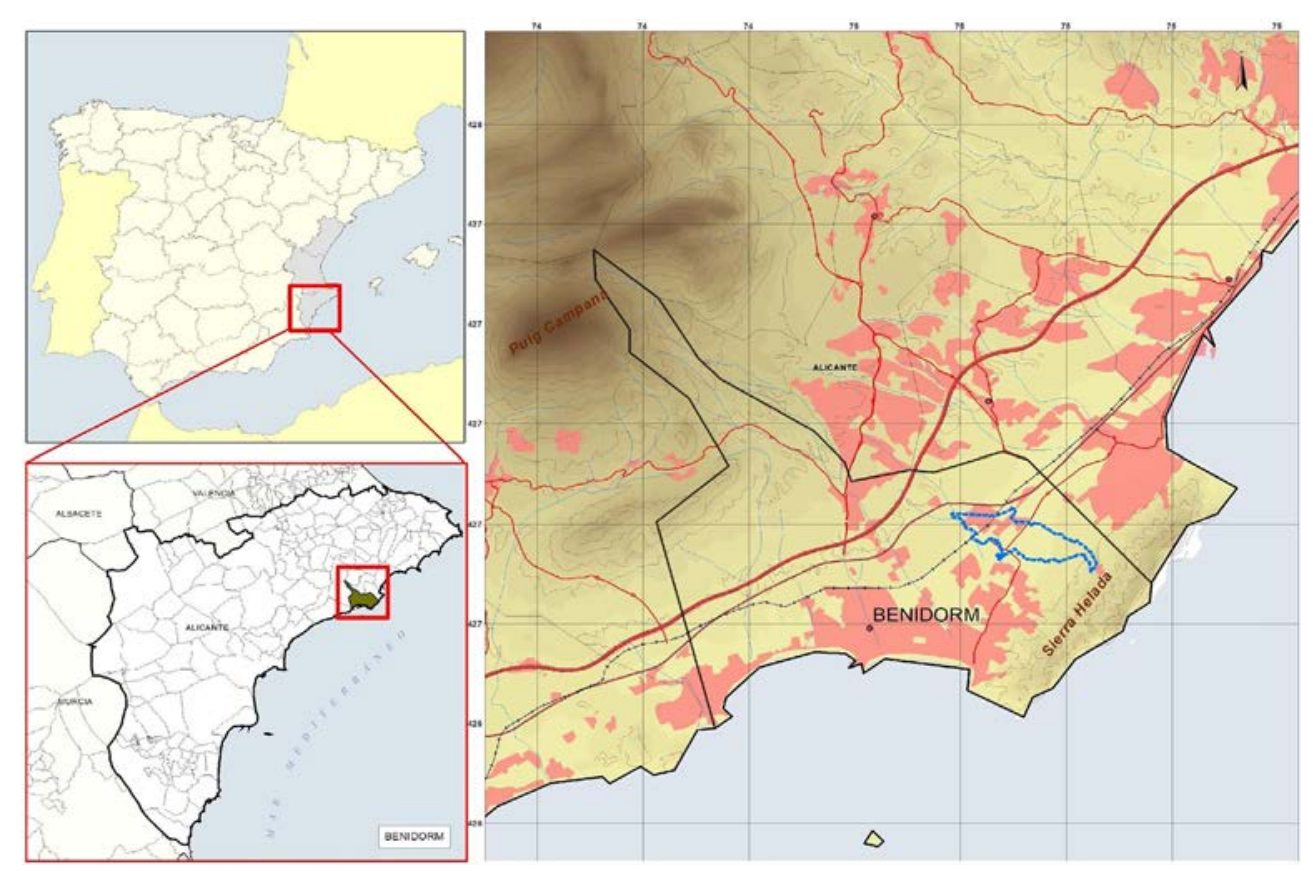

Figure 1: Location of the area under study.

\subsection{Manning's roughness coefficient}

The definition of Manning's roughness coefficient based on the SIOSE database is fairly simple, since land use is the only spatial variable involved. In the annexes of the SNCZI methodological guide [7], a series of tables are included where values of the Manning roughness coefficient are assigned for the land use from SIOSE as well as the use of CLC. It also includes data of common hydrological behaviour of both categorisations (CLC and SIOSE). Thus, for the assignment of Manning's value to each area using SIOSE, a calculation has been carried out combining Manning's value [9]. The result is shown in Fig. 2. This table has served as a basis to find coincidences between the hydrological behaviour of land use categorisations CLC and SIOSE. 


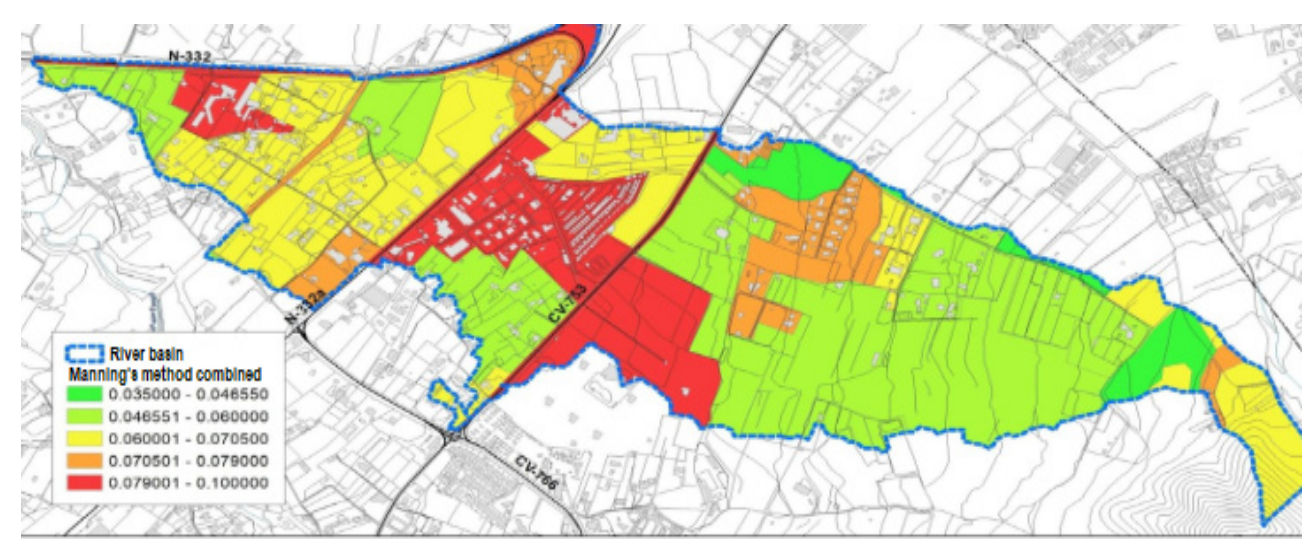

Figure 2: Manning's roughness coefficient from SIOSE.

\subsection{Threshold runoff $P_{0}$ estimation}

This variable is one of the most sensitive parameters in flood risk assessment studies, since a single change in its definition might lead to significant alterations in the result and, therefore, a very different flow rate, seriously affecting the flood-prone area. As mentioned in the justification, it is necessary to consider three spatial variables (slope, soil type and land use) when estimating threshold runoff $P_{0}$ estimation using SCS curve number method, and this hinders the use of SIOSE.

With the aim of providing an objective assessment of official cartographies about land use in hydrological analysis, threshold runoff $P_{0}$ has been calculated, as well as flow rates in different return periods (25, 100 and 500 years), using both, CLC and SIOSE. At the same time, the calculation of this flow rates are carried out using different hydrometeorological methods, in order to obtain a thorough characterisation that is going to allow us to draw accurate conclusions.

Finally, the same calculations are being implemented, but this time on the basis of the raster layer in Spanish threshold runoff, which can be obtained from the Ministry of Agriculture, Nature and Food Quality. Although $P_{0}$ raster layer (Fig. 3) at the Spanish level is not enough for small-sized basins ( $500 \mathrm{~m}$ pixel size), it has been included in the final comparison, just to have more baseline data.

Finally, the sources used for the calculation will be the following:

1. Calculation of the weighted threshold runoff based on the threshold runoff map of Spain.

2. Calculation of the weighted threshold runoff based on the land use layer from CLC.

3. Calculation of the weighted threshold runoff based on the land use layer from SIOSE:

a. Manual supervised method

b. Automated method

The sources used to characterise the other two variables involved in the calculation of threshold runoff were, on the one hand, IGN MDT05 layer for estimating the slope data using Travis' method [10] to obtain the slope threshold and, on the other hand, the Lithology layer from the former COPUT (thematic cartography of the region of Valencia in 1998) [11], for characterising soil types (Fig. 4). 


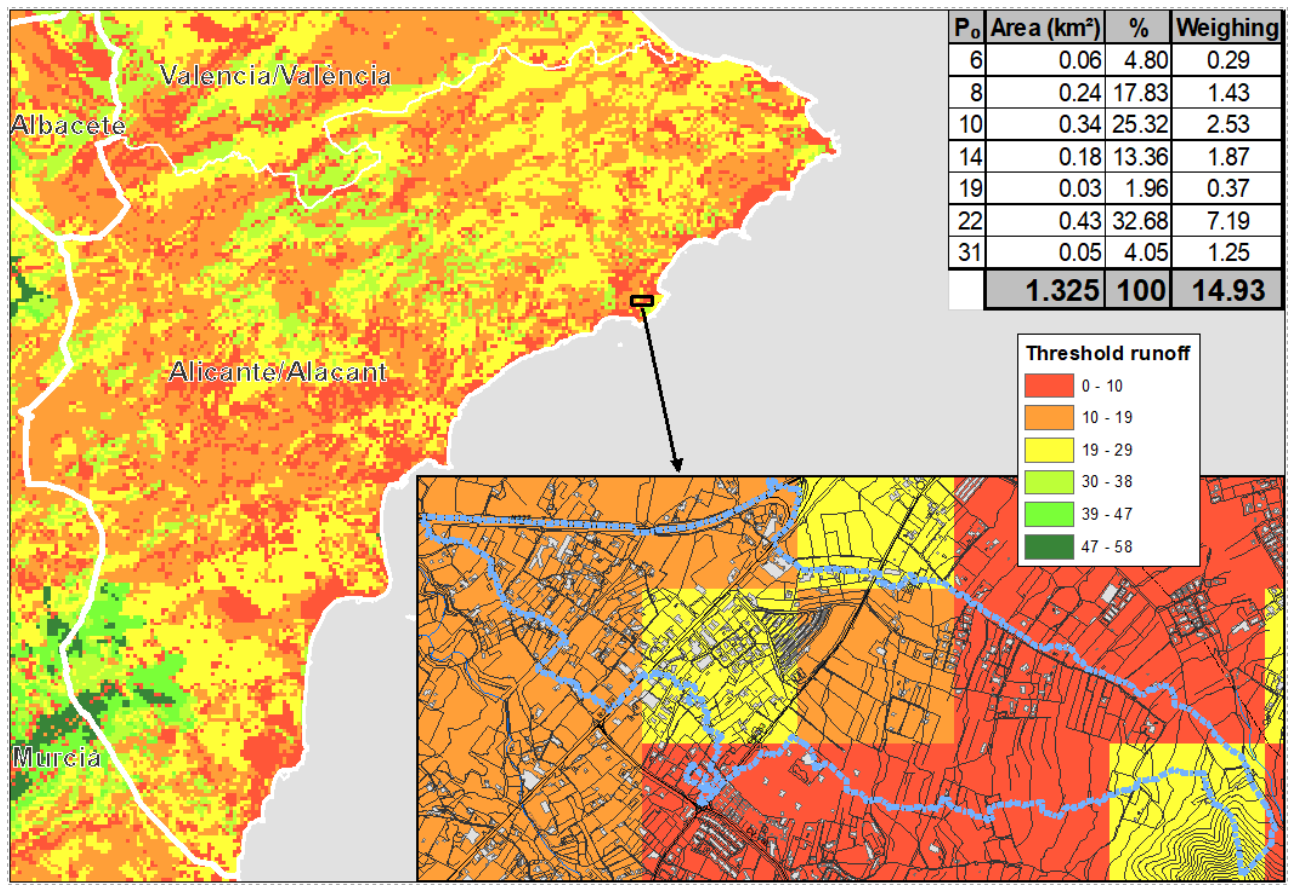

Figure 3: Initial value of threshold runoff $\left(P_{0}\right)$ for Spain with a pixel size of $500 \mathrm{~m}$.

(a)

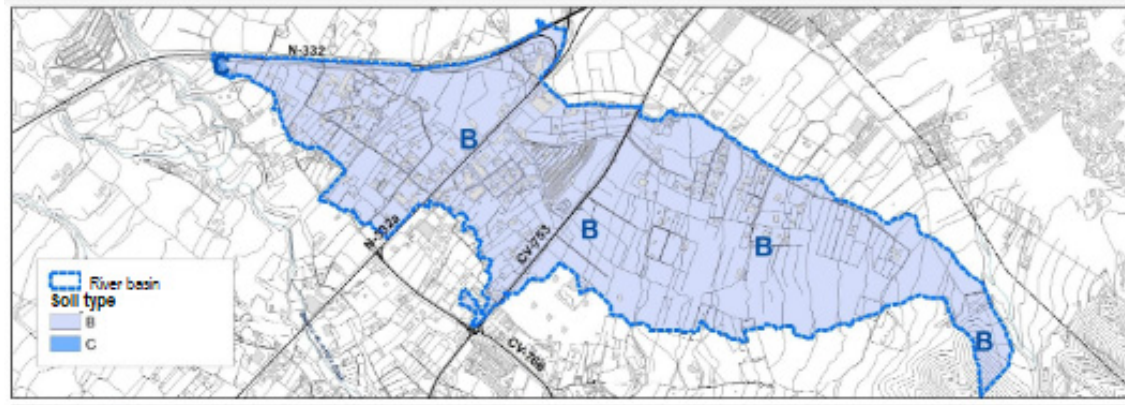

(b)

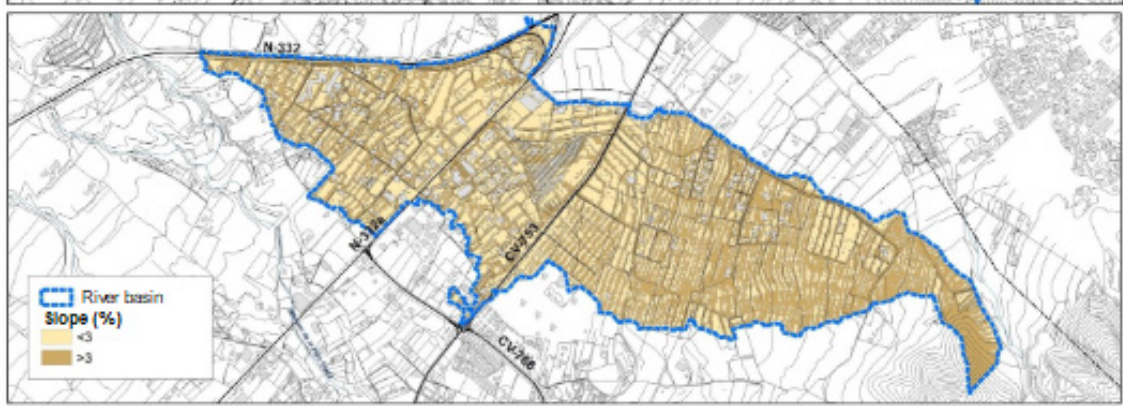

Figure 4: All other variables involved in the calculation of threshold runoff. (a) Soil type; and (b) Slopes. 
The different hydrometeorological methods used to calculate flow rates are:

A. Rational method.

B. Modified Témez's method.

C. Modified Témez's method, without rainfall derating factor (where $\mathrm{Ka}=1$ ).

D. Highway Instruction 5.2., 2016 updated version.

\subsection{Calculation of threshold runoff using CLC}

In order to calculate threshold runoff applying the SCS curve method on the basis of CLC layer, the equivalence table is found in both the Highway Instruction 5.2 [8] and the SNCZI specification [7]. The results are shown in Fig. 5.

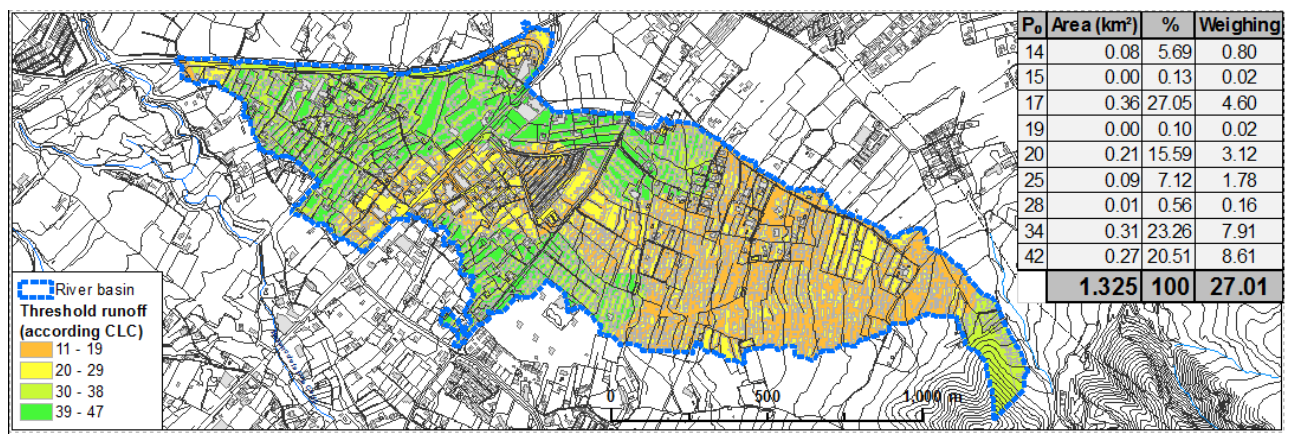

Figure 5: Threshold runoff value $\left(P_{0}\right)$ calculated a on the basis of land use from CLC.

\subsection{Calculation of threshold runoff based on the SIOSE database}

To calculate threshold runoff on a more appropriate scale, the SIOSE database will be taken as a reference, being aware that the same area in the database may encompass several land cover observations, and that occupation rates are represented with percentages. The main feature of SIOSE is that some of its polygons do not have a unique descriptor, like CLC, but a complex codification and, thus, a richer one. Every area has its own unique identifier, named ID POLYGON and it can be simple or compound. While the simple ones hold one descriptor, the compound areas have several land cover descriptors, they can be classified in regular covers, irregular covers and associations and their occupation rates are expressed as percentages.

This database design makes it difficult to carry out processes in which more than one spatial variable is involved, such as the calculation of $P_{0}$. For that reason, to enable the use of the rich information from SIOSE, two variants are proposed: the manual supervised method and the combined method.

\subsubsection{Manual supervised method}

In both cases, a unique hydrological behaviour must be allocated to a specific area from SIOSE, depending on the soil types in that area and the occupation rate in each of them. It is not a matter of setting an equivalence between CLC and SIOSE, as done in other methods [12], because it may introduce serious errors in the study of hydrological behaviour. In this case, it is required to allocate an identifier that represents the 
hydrological behaviour of different land uses in an specific area and, specially, their occupation rates.

Fig. 6 shows three examples of the SIOSE code. In the first one (Fig. 6(a)) the code represents a simple cover with a single identifier (Grassland - PST), which accounts for $100 \%$ of the area. In this case, allocation is simple, because the hydrological behaviour of grasslands is directly assigned to that area.

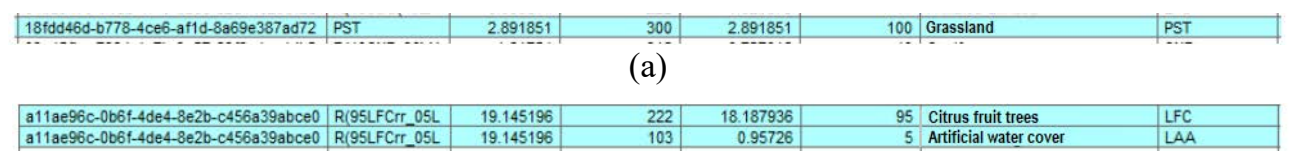

(b)

\begin{tabular}{|c|c|c|c|c|c|c|c|}
\hline $9 e b 326 a f-1 b 5 b-4 a 7 f-9 b 29-6 e 3406 a e 4993$ & $R(58$ UDS(40ZA & 15.381317 & 102 & 3.568465 & 23.2 & Wood green area & ZAU \\
\hline $9 e b 326 a f-1 b 5 b-4 a 7 f-9 b 29-6 e 3406 a e 4993$ & R(S8UDS(40ZA & 15.381317 & 101 & 3.122407 & 20.3 & Edification & EDF \\
\hline $9 e b 326 a f-1 b 5 b-4 a 7 f-9 b 29-6 e 3406 a e 4993$ & $R(58$ UDS(40ZA & 15.381317 & 104 & 1.338175 & 8.7 & Road, parking, pedestrian road & VAP \\
\hline $9 e b 326 a f-1 b 5 b-4 a 7 f-9 b 29-6 e 3406 a e 4993$ & R(58UDS(40ZA & 15.381317 & 121 & 0.892116 & 5.8 & Non built-up area & SNE \\
\hline $9 e b 326 a f-1 b 5 b-4 a 7 f-9 b 29-6 e 3406 a e 4993$ & R(58UDS(40ZA & 15.381317 & 300 & 3.076263 & 20 & Grassland & PST \\
\hline $9 e b 326 a f-1 b 5 b-4 a 7 f-9 b 29-6 e 3406 a e 4993$ & R(58UDS(40ZA & 15.381317 & 222 & 1.538132 & 10 & Citrus fruit trees & LFC \\
\hline $9 e b 326 a f-1 b 5 b-4 a 7 f-9 b 29-6 e 3406 a e 4993$ & R(58UDS(40ZA & 15.381317 & 212 & 1.076692 & 7 & Arable crops (not rice) & CHL \\
\hline $9 e b 326 a f-1 b 5 b-4 a 7 f-9 b 29-6 e 3406 a e 4993$ & R(58UDS $(40 Z A$ & 15.381317 & 111 & 0.769066 & 5 & Other structures & OCT \\
\hline
\end{tabular}

(c)

Figure 6: Table of attributes from SIOSE. (a) Example of an area from SIOSE with a land use of $100 \%$; (b) Example of compound cover from SIOSE with a land use distribution of $90 \%$; and (c) Example of an area with very similar occupation rates and with a significantly different hydrological behaviour.

In the second example (Fig. 6(b)) another usual combination is depicted, since it is a common land cover pattern in certain areas, increasing their occupation rate. In this case, the hydrological behaviour is determined by the most representative land cover in terms of its occupation rate, fruit trees in this case (Citrus - LFC), with a distribution of 95\%.

The third example (Fig. 6(c)) poses a classification problem, since there are compound covers with a wide variety of descriptors which entail highly differentiated hydrological behaviours, but with similar occupation rates. In this example, there are three differentiated hydrological behaviours (low thresholds of around $1 \mathrm{~mm}$, intermediate thresholds of $35 \mathrm{~mm}$ and thresholds varying from 20 to $25 \mathrm{~mm}$ ). Each of these three groups represents a $33 \%$ of the occupation rate in the area. Therefore, the allocated hydrological behaviour must be in between both extremes and towards the safest threshold in terms of flood risk assessment.

This manual assignment (Fig. 7) still has certain degree of uncertainty. As a solution, the combined method is proposed below.

\subsubsection{Combined method}

In order to prevent subjectivity in the manual method when assigning values, a second method named "combined method" (Table 1) is proposed, inspired by the one used for the assignment of Manning's roughness value.

In this method, the calculation is done on the basis that all information likeable to prevent this subjectivity is included in the table, that is, every land cover descriptor for each area along with its corresponding hydrological behaviour and occupation rate.

Intersecting slope an soil type layers with SIOSE land cover data poses a main drawback: the exact location of each member within a SIOSE compound cover is unknown. Hence we propose a tradeoff that consists of weighing each cover according to the occupation rates of each slope category and soil type within a SIOSE area. 


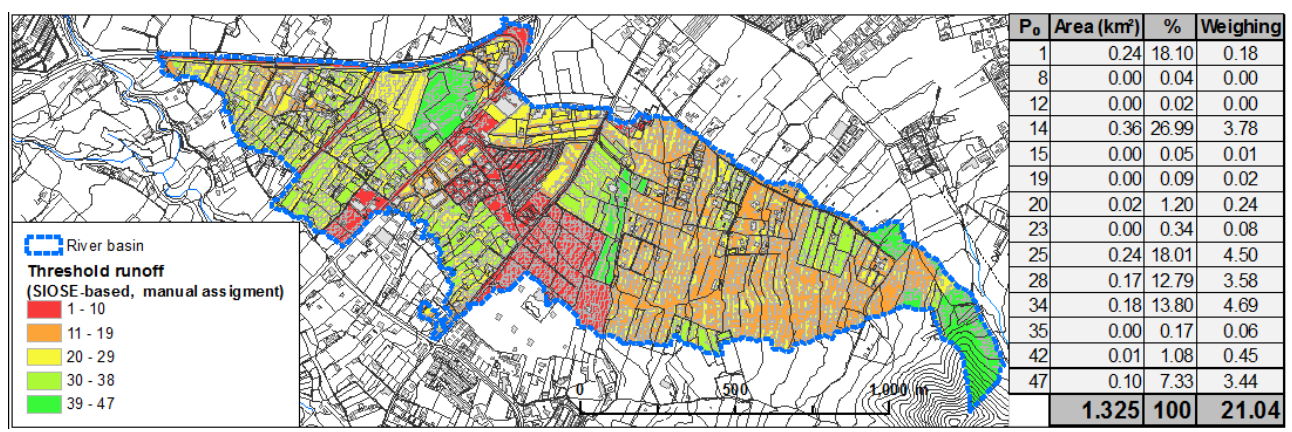

Figure 7: Threshold runoff value $\left(P_{0}\right)$ based on land use data from SIOSE, manual supervised method.

Table 1: Threshold runoff value $\left(P_{0}\right)$ based on land use data from SIOSE, combined method.

\begin{tabular}{|r|r|r|c|}
\hline $\mathbf{P}_{\mathbf{0}}$ & Area $\mathbf{( k m}^{\mathbf{2}} \mathbf{)}$ & \multicolumn{1}{|c|}{$\%$} & Weighing \\
\hline 0 & 0.01 & 0.39 & 0.00 \\
\hline 1 & 0.34 & 25.65 & 0.26 \\
\hline 8 & 0.00 & 0.01 & 0.00 \\
\hline 12 & 0.00 & 0.00 & 0.00 \\
\hline 14 & 0.16 & 12.21 & 1.71 \\
\hline 15 & 0.00 & 0.05 & 0.01 \\
\hline 19 & 0.00 & 0.09 & 0.02 \\
\hline 20 & 0.02 & 1.23 & 0.25 \\
\hline 23 & 0.04 & 2.67 & 0.61 \\
\hline 25 & 0.13 & 9.56 & 2.39 \\
\hline 28 & 0.16 & 12.23 & 3.42 \\
\hline 31 & 0.00 & 0.02 & 0.01 \\
\hline 34 & 0.18 & 13.40 & 4.56 \\
\hline 35 & 0.03 & 2.20 & 0.77 \\
\hline 42 & 0.01 & 1.12 & 0.47 \\
\hline 47 & 0.25 & 19.18 & 9.01 \\
\hline & $\mathbf{1 . 3 2 5}$ & $\mathbf{1 0 0}$ & $\mathbf{2 3 . 4 8}$ \\
\cline { 2 - 4 } & \multicolumn{2}{|r}{}
\end{tabular}

4 RESULTS

As mentioned in the methodology section, to perform a thorough assessment of results, it has been decided to also include the results from the calculation based on IGME map for Spain, as well as CLC land use data. At the same time, the flow rate details for different return periods have been calculated using the four hydrometeorological methods that were previously mentioned (method A, B, C and D). The final result from the different calculation sources and methods is given in Table 2.

As seen in Table 2, the lowest threshold is the result from the calculation for Spain (Source 1), which is $14.93 \mathrm{~mm}$. This calculation has low accuracy, because the pixel size is $500 \mathrm{~m}$, clearly not enough for small-sized basins. Flow rates are much higher, twice the value of the other calculations. Therefore, even though this is not the most appropriate scale, the flow rate result is higher, and we keep in the safe side. 
Table 2: Table of results.

\begin{tabular}{|c|c|c|c|c|c|c|c|c|c|c|}
\hline & \multicolumn{9}{|c|}{ Return period } & \multirow{4}{*}{$P_{0}$} \\
\hline & \multirow{2}{*}{\multicolumn{3}{|c|}{$\begin{array}{l}25 \text { years } \\
\text { Methods }\end{array}$}} & \multirow{2}{*}{\multicolumn{3}{|c|}{$\begin{array}{l}100 \text { years } \\
\text { Methods }\end{array}$}} & \multirow{2}{*}{\multicolumn{3}{|c|}{$\begin{array}{c}500 \text { years } \\
\text { Methods }\end{array}$}} & \\
\hline & & & & & & & & & & \\
\hline & $\mathbf{A}$ & $B$ and $D$ & C & $\mathbf{A}$ & $B$ and $D$ & $\mathbf{C}$ & $\mathbf{A}$ & $B$ and D & C & \\
\hline Source 1 & 23.98 & 19.74 & 20.1 & 45.2 & 37.24 & 37.8 & 78.3 & 64.69 & 65.6 & 14.93 \\
\hline Source 2 & 9.16 & 7.47 & 7.67 & 22.2 & 18.24 & 18.6 & 44.9 & 36.92 & 37.6 & 27.01 \\
\hline Source 3a & 14.88 & 12.2 & 12.5 & 31.3 & 25.76 & 26.2 & 58.5 & 48.23 & 49 & 21.04 \\
\hline Source 3b & 12.27 & 10.04 & 10.3 & 27.2 & 22.36 & 22.8 & 52.4 & 43.16 & 43.9 & 23.48 \\
\hline
\end{tabular}

The outcome from Source 2 (CLC) yields the highest threshold value $(27.01 \mathrm{~mm})$, and for that reason it will provide lower flow rates. Although this is the method suggested by the competent government bodies in this field, baseline data are not accurate enough, and, when threshold runoff value increases, which means more water infiltrating the soil before runoff generation, flow rates decrease, and thus yield the lowest results.

The next values correspond to the analysis performed with the Source 3 (SIOSE), which guarantee an adequate scale, a higher thematic resolution, updates every 3 years, open and standardised official data. On the other hand, SIOSE's descriptive data model requires additional processing since it hampers one-to-one relations with the other two variables (slope and land type) involved in the calculation of $P_{0}$. The results from the calculation with this source for the manual method (3a) and the combined method (3b) are $21.04 \mathrm{~mm}$ and $23.48 \mathrm{~mm}$ respectively. Even though, the manual method brings somewhat subjectivity, since the assignment criteria depends on the technician in charge, this assignment remarkably tends to remain always on the safe side. Finally, although one must bear in mind that in the combined method, the distribution of the other two variables (land type and slope) will affect to every land cover represented in an area, this method remains the one providing the highest level of objectivity to the calculation.

\section{DISCUSSION}

As for the methods proposed in this paper, the manual method implies subjectivity, since it is based on a supervised assignment, which depends on the technician's skills, experience and expertise. A correct implementation of this method requires previously assigning hydrological behaviour to a training set of areas so that subsequent extrapolation is made based on well-defined criteria. This way, assignment discrepancies between similar areas can be narrowed. Indeed, a key point in manual assignment is to design a protocol on these criteria to be applied in similar areas and, thus, prevent subjective assessment by extrapolating this estimation to the characterisation of areas that meet the same conditions.

Nevertheless, the manual assignment of values remains highly subjective, even if it is done cautiously, valuing greater certainty and trying to continually learn in the assignment in order to extrapolate the information to similar areas. Furthermore, this method implies a simplification of the information collected from SIOSE areas, which means discarding SIOSE's thematic resolution, and even worse, producing a reclassification of the values which tends to replicate the structure of CLC.

On the other hand, the combined method is by far the most objective one. It preserves information richness and encourages the use of updated, open, standardised official data on an appropriate working scale. The result of $P_{0}$ calculation with this method is $23.48 \mathrm{~mm}$, in 
between the values obtained with CLC $(27.01 \mathrm{~mm})$ source used in SNCZI and the $21.04 \mathrm{~mm}$ from the manual method calculation. This result is the most logical one, since its value is between the one obtained from a cartography with an insufficient scale and one obtained from the manual method, which tends to stay on the safe side.

Once the methodology has been tested, the next step will be the automation of the process. However, before proceeding, the application of each methodology should be extended to a greater number of basins. In this way, more reference values will be available, which will allow a thorough understanding of the characterisation of hydraulic behaviour based on SIOSE land use data. In the end, working with detailed cartography like SIOSE (1:25.000 until 2018 and 1:10.000 since 2018), will provide the accuracy that the model lacks and a richer results in the flood risk assessment.

However, it has to be borne in mind that the accuracy obtained in the calculation of threshold runoff using the SIOSE database is not useful at all if the other spatial variables are not estimated with the same accuracy. The soil type variable, in which there are only four types defined by hydrological group, is based on a 1:50.000 scale cartography, which causes serious inaccuracies in the baseline data of the areas under study. An official cartography with an appropriate scale is therefore essential for the representation of the variable. In general, the use of official cartography as a reference is vital for such studies and for the definition of parameters, since it smooths the work, guarantees quality, and prevents human mistakes and any kind of subjectivity in the calculation.

Finally, a thorough understanding of the hydrological behaviour of land use is vital for the integral management of basins, and it is not just about the already existing land uses, but also about the newly proposed ones. A detailed analysis of the use of a basin would enable a coherent allocation of new areas and would make it easy to know which new land uses can be allowed without increasing flood risk. In this sense, the analysis of threshold runoff in a specific drainage basin should be a key tool to correct the errors of the past or, at least, to avoid remaking them, with the ultimate goal of achieving a responsible land-use planning.

\section{ACKNOWLEDGEMENTS}

The authors are grateful to the SIOSE-INNOVA Project (CSO2016-79420-R AEI/FEDER UE) and Interuniversity Institute of Geography, University of Alicante.

\section{REFERENCES}

[1] Bescos Atin, A., Camarasa Belmonte, A.M. \& Al, E., Elaboración de cartografía de zonas inundables. Aplicación al Llano de Inundación del Río Arga (Navarra). Ser. Geográfica, 9, pp. 219-236, 2000.

[2] Camarasa Belmonte, A.M., García López, M.J. \& Pascual, J.A., Análisis mediante SIG de los parámetros de producción de escorrentía. El acceso a la inf. Espac. Y las nuevas tecnol. Geográficas, pp. 49-63, 2006.

[3] Almánzar, R. \& Pascual, J.A., Análisis de sucesos productores de caudal en pequeñas cuencas mediterráneas como apoyo a la gestión integrada y sostenible del agua. VII Congr. Ibérico sobre Gestión y Planif. del Agua Ríos Ibéricos +10, pp. 1-6, 2011.

[4] López García, M.J., Camarasa Belmonte, A.M. \& Mateu Bellés, J.F., Cambios en los usos del suelo y producción de escorrentía en ramblas mediterráneas: Carraixet y Poyo (1956-1998). Bol. la Asoc. Geogr. Esp., 44, pp. 69-94, 2007.

[5] Témez, J.R., Cálculo hidrometeorológico de caudales máximos en pequeñas cuencas naturales, MOPU Dirección General de Carreteras, 1978.

[6] Fomento, Geoportal SIOSE, 2019. www.siose.es/. 
[7] Sánchez Martínez, F.J., Lastra Fernández, J., Andrés Moreno, C., García-Olivo González, M., Marcuello Olona, C. \& Jiménez Álvarez, A., Guía metodológica para el desarrollo del Sistema Nacional de Cartografía de Zonas Inundables, Spanish Ministry, 2011.

[8] Ministry of Public Works and Urban Planning. Spanish Government, Spanish normative: Orden FOM/298/2016, de 15 de febrero, por la que se aprueba la norma 5.2 - IC drenaje superficial de la Instrucción de Carreteras. Boletín of. del Estado, 60, March 10, pp. 18882-19023, 2016.

[9] González, J., García, O., Crespo, A., Gómez, M. \& Cea, L., Predicción de inundaciones originadas por precipitaciones extremas mediante el módulo hidrológico de Iber. V. Jornadas Ing. del Agua, pp. 1-15, 2017.

[10] Castillejo, I., Fernández, P., Garcia-Ferrer, A. \& Sánchez, M., Estudio comparativo de los distintos métodos de cálculo de pendientes derivados de modelos digitales de elevación, 1, p. 13, 2004.

[11] Martínez J. \& Balaguer, J., Litología, aprovechamiento de rocas industriales y riesgo de deslizamiento en la Comunidad Valenciana, Publicaciones Divulg. Técnica, p. 66, 1998.

[12] Cantarino Martí, I., Elaboración y validación de un modelo jerárquico derivado de SIOSE. Rev. Teledetec., 39, pp. 5-21, 2013. 